\title{
The tempo of trophic evolution in small-bodied primates
}

2

3
Running title: Trophic evolution in small-bodied primates

Jeremiah E. Scott

Department of Medical Anatomical Sciences

College of Osteopathic Medicine of the Pacific

Western University of Health Sciences

309 East Second Street

Pomona, California 91766

U.S.A.

jeremiah.e.scott@gmail.com
Keywords body size, diet, insectivory, herbivory, heterotachy 


\section{$44 \quad 1$ | INTRODUCTION}

45 Primates exhibit an impressive diversity of trophic strategies. Among extant members of the

46 order, frugivory is the most widespread primary strategy, but folivory is also common (Gómez \&

47 Verdú, 2012; Kay \& Covert, 1984). The clade also includes specialized lineages such as the graminivorous gelada (Theropithecus gelada) of the Ethiopian Highlands, the tree-gouging,

49 exudativorous marmosets (genera Callithrix, Mico, Callibella, and Cebuella) of Amazonia and

50 the Atlantic Forest, and the exclusively faunivorous tarsiers (family Tarsiidae) of the Malay

51 Archipelago (Fleagle, 2013). Explaining how this diversity arose — and particularly how it has

52 been shaped by other aspects of primate biology - is a major goal of evolutionary primatology.

Body size has been recognized as an important influence on primate trophic evolution

54 since Kay (1975) noted that folivores are mostly large-bodied whereas insectivores are mostly

55 small. The correlation between body size and diet has been attributed to two other size-related

56 trends (Kay, 1975; Kay \& Covert, 1984; Kay \& Hylander, 1978; Kay \& Simons, 1980). First,

57 because insects are small, dispersed, and often elusive, acquiring enough of them to meet

58 metabolic requirements becomes more challenging as body size increases and is probably

59 physiologically impossible above a certain threshold without specializing on social insects

60 (McNab, 1984). Second, as body size decreases, digestive retention time becomes shorter and

61 metabolic rate per unit mass increases, making it difficult for small-bodied primates to extract

62 sufficient nutrition from leaves, which are resistant to chemical digestion and must be slowly

63 fermented in the gut (Lambert, 1998). These arguments have also been invoked to explain why

64 large-bodied frugivorous primates rely on leaves as their main source of dietary protein whereas

65 small-bodied frugivores are dependent on insects (Kay \& Simons, 1980; Kay \& Covert, 1984).

66 Size differentiation between herbivores and faunivores is pervasive across mammals (Price \& 
67 Hopkins, 2015; Grossnickle, 2020), indicating that the pattern found in primates is a general

68 feature of mammalian biology.

The distribution of trophic strategies within small-bodied primates has generated

70 additional hypotheses of constraint on the evolution of insectivory. Although insects are an

71 important resource for many diurnal primates (e.g., Digby, Ferrari, \& Saltzman, 2007; Kinzey,

72 1992; Souza-Alves, Fontes, Chagas, \& Ferrari, 2011; Zimbler-DeLorenzo \& Stone, 2011),

73 insectivory as a primary trophic strategy (i.e., at least $50 \%$ a species' diet) is found mainly in

74 nocturnal lineages (Figure 1). The reason for the rarity of insectivory in small-bodied diurnal

75 lineages is unclear, but one hypothesis that has been proposed is that competition with diurnal

76 birds has limited the ability of primates to become established in the diurnal arboreal insectivore

77 niche (Cartmill, 1980; Charles-Dominique, 1975; Ross, 1996). This idea is difficult to test, but

78 direct interactions between the two clades certainly do occur (Heymann \& Hsia, 2015), and there

79 is evidence that such interactions have had an influence on the distribution of species in each

80 clade (Beaudrot et al., 2013a, 2013b).

A long history of adaptation to herbivory has also been identified as a possible constraint.

82 In his discussion of primate origins, Rosenberger (2013) advocated for the idea that frugivory

83 was the formative trophic influence on early primate evolution, responsible for many of the

84 apomorphies that distinguish primates from other mammals (Sussman, 1991; Sussman,

85 Rasmussen, \& Raven, 2013; Szalay, 1968). As a consequence, he argued, a primarily

86 insectivorous diet presents primates with "intense selective challenges" (Rosenberger, 2013, p.

87 886), making it difficult for them to switch from herbivory to insectivory. Studies of acidic

88 mammalian chitinase genes (CHIAs) provide support for the idea that some primate lineages

89 have experienced changes to their digestive biology that may decrease the likelihood of 
90 insectivory evolving or persisting (Emerling, Delsuc, \& Nachman, 2018; Janiak, Chaney, \&

91 Tosi, 2018). However, in contrast to the global constraint proposed by Rosenberger, the

92 distribution of CHIA pseudogenes and deletions among extant species indicates that gene

93 functionality has been maintained by selection in some primate lineages and lost multiple times

94 in others (Emerling et al., 2018; Janiak et al., 2018). As noted by the authors of the CHIA studies,

95 this pattern of evolution is consistent with the hypothesis that insectivory was important for early

96 primates (Cartmill, 1974, 1992, 2012), with various clades becoming more specialized for

97 herbivory over time, perhaps resulting in variation across the primate tree in the ability to exploit

98 insects as a primary dietary resource.

If these constraints, or others, are operating in primates, then they should manifest at the

100 macroevolutionary level as heterogeneity among lineages in the rate of trophic evolution. For

101 example, the hypothesis that diurnality limits the evolution of insectivory predicts that small-

102 bodied anthropoids, which are mostly diurnal, will have a lower rate of transition between

103 trophic states than other small-bodied primate lineages, which are mostly nocturnal.

104 Evolutionary rates have been used to test hypotheses of constraint or to make a posteriori

105 inferences of constraint in a diverse set of organismal traits, including flower size in plants

106 (Barkman et al., 2008), forelimb morphology in marsupials (Cooper \& Steppan, 2010), niche

107 evolution in damselfishes (Litsios et al., 2012), growth form in angiosperms (Beaulieu, O’Meara,

108 \& Donoghue, 2013), and habitat shifts in diatoms (Nakov, Beaulieu, \& Alverson, 2019). The

109 goal of the present study is to evaluate the idea that trophic evolution is constrained in some

110 small-bodied primate lineages by testing for variation in transition rates between insectivory and

111 herbivory against the null hypothesis that a single rate can explain the distribution of insectivory

112 and herbivory across the primate tree. 


\section{$114 \quad 2$ |MATERIALS AND METHODS}

\section{$115 \quad 2.1 \mid$ Tree and sample}

116 The analyses reported here were conducted using the phylogenetic topology estimated by

117 Springer et al. (2012) for 367 extant primate taxa. This tree was pruned so that only species-level

118 taxa recognized by Groves (2005) were included, resulting in a tree with 307 tips. Springer et al.

119 provided four sets of divergence dates for the tree based on different assumptions about variation

120 in rates of molecular evolution among lineages and the certainty of fossil calibrations. Two of the

121 timetrees were used for the present study: one that assumed autocorrelated rates of molecular

122 evolution with soft-bounded constraints on fossil calibrations, and one that assumed

123 autocorrelated rates but with hard-bounded constraints. These two trees were preferred over the

124 two that assumed independent rates of molecular evolution because autocorrelated rates provide

125 a much better fit to the primate molecular data and appear to be more biologically realistic (dos

126 Reis et al., 2018). The trees are available in the Supporting Information (Text S1 and Text S2).

127 Species were classified as insectivorous or herbivorous using primary field reports or

128 recent reviews that compiled information on dietary composition from such reports. A species

129 was considered insectivorous when insects and other small fauna constituted at least $50 \%$ of its

130 diet. For some species, dietary percentages were not available. In those cases, assignments were

131 made using qualitative descriptions from experts as long as the characterizations were

132 compatible with quantitative data for the species' closest living relatives. A total of 26 species

133 were identified as insectivorous (Table 1). The remaining taxa were categorized as herbivorous,

134 which subsumes frugivory, seed predation, folivory, exudativory, and graminivory (see Table S1

135 in the Supporting Information for the full list of taxa and character coding). 
Species were further divided into small-bodied and large-bodied using literature compilations of body mass (Smith and Jungers, 1997; Jones et al., 2009; Fleagle, 2013). Two

138 sets of analyses were performed using different size thresholds to evaluate whether the value

139 used to dichotomize body size affects interpretations: $800 \mathrm{~g}$ and $1 \mathrm{~kg}$. All species were assigned

140 to a size category based on female body mass, given that females are considered more sensitive

141 to energetic constraints than males (e.g., Gordon, Johnson, \& Louis, 2013). Taxa without data on

142 body mass were assigned to a size category when their position relative to the threshold could be

143 assumed with high confidence (e.g., all callitrichines are smaller than $800 \mathrm{~g}$ ).

144 The size and diet classifications were combined to create a three-state character: small-

145 insectivorous, small-herbivorous, and large-herbivorous. This character was treated as ordered,

146 with direct transitions between small-insectivorous and large-herbivorous prohibited (i.e.,

$147 \mathrm{SI} \leftrightarrow \mathrm{SH} \leftrightarrow \mathrm{LH})$. This coding scheme allowed transitions between trophic states within small-

148 bodied lineages to be isolated in the analysis without compromising phylogenetic sampling by

149 excluding large-bodied lineages.

\section{$151 \quad 2.2 \mid$ Models of trait evolution}

152 Transition rates between character states were estimated using the multistate speciation and 153 extinction model (MuSSE) in the package diversitree (FitzJohn, 2012) for R (R Core Team, 154 2019). The hypothesis of variation in rates of trophic evolution was tested using diversitree's 155 make.musse.split function, which splits subclades (foreground clades) from the rest of the tree 156 (paraphyletic background) and allows each partition to have separate rate classes. The locations

157 of the splits are selected prior to analysis. Three foreground clades were used for this study:

158 Anthropoidea, Lemuriformes, and Lorisiformes. Initially, models with one split — one foreground 
159 clade and the background - were examined. Depending on the results of those analyses, the

160 model set was expanded to include models with two foreground clades.

For each character state, MuSSE estimates up to three parameters: the transition rate out

162 of the state $(q)$, the speciation rate for lineages in the state $(\lambda)$, and the extinction rate for lineages

163 in the state $(\mu)$. Thus, a MuSSE model for an ordered three-state character and no splits will have

164 as many as $k=10$ estimated parameters. Adding a single split will double that number to $k=20$,

165 which is almost certainly too many for the size of the primate tree. To reduce the parameter set to

166 a more appropriate size, the following constraints were imposed. First, speciation and extinction

167 rates were not allowed to vary by character state or across partitions. Second, transition rates

168 between insectivory and herbivory in small-bodied lineages were set equal to each other within

169 partitions (i.e., $q_{\mathrm{IH}}=q_{\mathrm{HI}}$, where $q_{\mathrm{IH}}$ is the rate from insectivory to herbivory, and $q_{\mathrm{HI}}$ is the rate

170 from herbivory to insectivory). Previous analysis of this data set using an unpartitioned tree

171 found that the symmetric-rates model for transitions between trophic states provides a better fit

172 to the data than a model that allows rate asymmetry (i.e., $\left.q_{\mathrm{IH}} \neq q_{\mathrm{HI}}\right)$ (Scott, 2019). Preliminary

173 model comparisons using Akaike's information criterion indicated that the symmetric-rates

174 assumption is also justified within the partitions examined here. For transitions between size

175 classes among herbivores, there is strong support for rate asymmetry, with the rate into the large-

176 bodied state being several times higher than the rate into the small-bodied state across the

177 primate tree (Scott, 2019). Thus, size transition rates were allowed to vary within partitions.

178 These constraints resulted in two-partition models with $k=8$ parameters: one trophic transition

179 rate for each partition, two size transition rates for each partition, and one speciation rate and one

180 extinction rate for the entire tree. A three-partition model (two foreground clades and the

181 paraphyletic background) has at least one more parameter $(k=9)$ for the second foreground 
182 clade's trophic transition rate and, depending on the results, two additional parameters for that

183 clade's size transitions $(k=11)$.

\subsection{Bayesian analysis of rate estimates}

Uncertainty in the maximum-likelihood estimate for each transition rate was examined

187 using a Bayesian approach to approximate each parameter's posterior distribution. This part of

188 the analysis was conducted with Markov chain Monte Carlo (MCMC) using diversitree's mcmc

189 function (FitzJohn, 2012). Markov chains were generated following the procedures outlined in

190 Johnson, FitzJohn, Smith, Rausher, \& Otto (2011) and FitzJohn (2012), including their use of an

191 exponential prior distribution with a mean of twice the net diversification rate (i.e., speciation

192 rate minus extinction rate) for the entire tree. The chains were run for 120,000 generations, with

193 the first 20,000 being discarded as burn-in. The remaining generations were thinned by sampling

194 every tenth generation, resulting in a final sample of 10,000 generations for further analysis. The

195 R package coda (Plummer, Best, Cowles, \& Vines, 2006) was used to examine MCMC

196 diagnostics on the thinned chains. Effective sample sizes for transition rates were high $(n>8200$,

197 typically $n>9000)$, autocorrelation among generations for each parameter was low $(r<0.07$,

198 typically $r<0.03$ ), and trace plots indicated convergence.

199 The posterior distributions for the parameter estimates were used to compute posterior

200 probabilities for differences between transition rates. The posterior probability that $q_{i}$ is greater

201 than $q_{j}$ is simply the proportion of MCMC samples for which that statement is true (Goldberg et

202 al., 2010). Such comparisons were made across partitions (e.g., Anthropoidea versus the

203 background) and within partitions in the case of size transitions (e.g., the rate of transition into

204 the large-bodied state versus the rate into the small-bodied state in Anthropoidea). Because the 
205 posterior distributions for Lorisiformes were strongly right-skewed, rates were log-transformed

206 (base $e$ ) for visual presentation, but all quantitative comparisons were made using the

207 untransformed rates.

208

$209 \quad 3$ | RESULTS

\section{$210 \quad 3.1$ | Two-partition models}

211 With Anthropoidea split from the rest of the tree, there is moderate support for two rates of

212 transition between insectivory and herbivory in small-bodied lineages. Anthropoids have a lower

213 rate than other primates (Figure 2A): the maximum-likelihood estimate for the background rate

214 is approximately 5-7 times higher than the estimate for anthropoids (Table S2). The posterior

215 probabilities for rate heterogeneity in this partitioning scheme range from $P P=0.906$ to 0.959 ,

216 depending on the tree and size threshold (Table 2). Support is highest when using a size

217 threshold of $1 \mathrm{~kg}$ and the tree with soft-bounded constraints on fossil calibrations.

218 There is strong support for asymmetry in size transition rates among anthropoids, where

219 transitions from small to large occur at a much higher rate than transitions in the reverse

220 direction $(P P>0.99$; Figure $2 \mathrm{~B})$. In other primates, there is no evidence for such rate asymmetry

$221(P P<0.70 ;$ Figure $2 \mathrm{C})$. This difference in the pattern of size evolution is driven by the very low

222 transition rate out of the large-bodied state in anthropoids. This rate differs from the other size

223 transition rates with high posterior probability $(P P>0.98)$, whereas the other three rates cannot

224 be statistically distinguished from each other $(P P<0.85$; compare Figure $2 \mathrm{~B}$ and $2 \mathrm{C})$.

225 Given the strong support for these contrasting patterns of size evolution, the remaining

226 two-partition models were modified to allow anthropoids to have their own set of size transition

227 rates while constraining the rest of the tree to have a second set of size transition rates, regardless 
228 of how the tree was partitioned for the analysis of trophic transition rates. Thus, these models

229 have two partitions for trophic transition rates and two partitions for size transition rates. The

230 model that allowed Lorisiformes to have a distinct trophic rate produced the strongest support for

231 trophic rate heterogeneity among the two-partition models (Figure 3). In this case, lorisiforms

232 have a rate of trophic evolution that is approximately 4-6 times higher than the background rate

233 with high posterior probability $(P P>0.98$; Table S3). The results from the model that allowed

234 Lemuriformes to have a distinct trophic rate indicate no support for trophic rate heterogeneity

$235 \quad(P P<0.70 ;$ Figure 4; Table S4).

$237 \quad 3.2 \mid$ Three-partition model

238 The two-partition analyses suggest three possibilities: (1) that anthropoids have a lower trophic

239 transition rate than other primates, (2) that lorisiforms have a higher rate than other primates, or

240 (3) that the two-partition models do not adequately describe the degree of rate heterogeneity in

241 primates. To distinguish among these alternatives, a three-partition model with anthropoids and

242 lorisiforms both foregrounded was constructed. This model allowed each partition to have its

243 own rate of trophic evolution, with size transition rates partitioned as above (i.e., anthropoids

244 versus all other primates, including lorisiforms; Table S5). Analysis of this model indicates that

245 the anthropoid trophic rate cannot be clearly distinguished from the background rate $(P P<0.90)$,

246 that there is moderate support for lorisiforms having a higher trophic rate than the background

$247 \quad(0.90<P P<0.96)$, and that anthropoids and lorisiforms are very unlikely to be characterized by

248 a common trophic rate $(P P>0.98)$ (Table 3; Figure 5). These results suggest that, of the models

249 considered here, the two-partition model with Lorisiformes as the foreground clade provides the

250 best description of primate trophic evolution. 


\section{4 | DISCUSSION}

\section{$253 \quad 4.1$ | Activity pattern and trophic evolution}

254 The rate heterogeneity detected here supports the idea that trophic evolution has been more labile

255 in some small-bodied primate lineages than in others. The rarity of primarily insectivorous

256 anthropoids has focused attention on this clade and the possibility that some aspect of diurnal

257 ecology is a constraint on trophic evolution in primates (Cartmill, 1980; Charles-Dominique,

258 1975; Ross, 1996; Scott, 2019). The results of the present study challenge this idea by showing

259 that a single rate of transition between insectivory and herbivory can explain the distribution of

260 trophic strategies among small-bodied lineages of mostly diurnal anthropoids and nocturnal

261 lemurs and tarsiers. Insectivorous anthropoids and lemurs are nested deeply among herbivorous

262 lineages, indicating that insectivory is an evolutionarily recent phenomenon in these two clades

263 (Figure 1). Thus, despite differences in activity pattern, extant anthropoids and lemurs appear to

264 be characterized by similar trophic evolutionary histories where herbivory has predominated and

265 shifts to insectivory have been infrequent.

266 What distinguishes anthropoids in this analysis is their pattern of size evolution. In

267 contrast to other primates, which are characterized by symmetric rates of transition into and out

268 of the large-bodied state, anthropoids exhibit high rate asymmetry favoring shifts into the large-

269 bodied state. This result is not surprising in light of the well-known differences in the distribution

270 of body size among primate clades (e.g., Charles-Dominique, 1975; Fleagle, 1978, 2013;

271 Jungers, 1984). The prevalence of large body size (>1 kg) in anthropoids is thought to be one of

272 the solutions to the problem of trophic competition with diurnal birds, allowing anthropoids to

273 specialize on herbivorous resources that birds cannot typically access (e.g., leaves and 
274 mechanically protected fruits; Charles-Dominique, 1975; Ross, 1996). The results of this study

275 are consistent with this idea, but they do not constitute additional evidence beyond the

276 observation that anthropoids tend to be larger than diurnal birds. Diurnality can be considered an

277 indirect influence on the distribution of insectivory across the primate tree to the extent that it

278 increases the likelihood that large body size will evolve and persist. This effect is magnified by

279 the tendency of diurnal lineages to diversify and accumulate at a higher rate than nocturnal

280 lineages (Magnuson-Ford \& Otto, 2012; Santini, Rojas, \& Donati, 2015; Scott, 2018, 2019).

281 However, the results of this study suggest that activity pattern does not have an effect on the rate

282 of transition between herbivory and insectivory among small-bodied primates.

Because the broad-scale phylogenetic approach adopted here does not address the

284 possibility that lineage-specific factors have produced similar patterns of trophic evolution in

285 diurnal anthropoids and nocturnal lemurs, these results should not be viewed as a decisive

286 rejection of the idea that diurnality is a constraint on primate trophic evolution. Studies

287 conducted at a much finer scale of resolution may reveal different processes operating in each

288 clade and establish equifinality. However, given the current state of knowledge, the low

289 frequency of insectivory among small-bodied diurnal anthropoids does not appear to be unusual

290 and therefore in need of explanation. Instead, it is the lorises and galagos that stand out relative

291 to other small-bodied primates in having a greater tendency to shift between trophic states.

\subsection{Commitment to herbivory as a constraint on the evolution of insectivory}

The pattern of rate heterogeneity found in primates is consistent with the idea that

295 adaptive commitment to herbivory has reduced the likelihood that insectivory will evolve or

296 persist in some lineages. There are two ways to interpret the pattern of rate heterogeneity in this 
context. The first posits that the low rate of transition between trophic states found in most of the

298 primate tree is plesiomorphic, meaning that trophic evolution has been conservative for much of

299 the clade's history. This inference, combined with the prevalence of herbivory among extant

300 lineages, aligns with the view that many of the apomorphies that unite primates originated as

301 adaptations for acquiring angiosperm products, and that this aspect of the clade's evolutionary

302 history has biased primates against adopting insectivory as a primary trophic strategy

303 (Rosenberger, 2013; Sussman et al., 2013). It follows that the higher rate of trophic evolution

304 found in lorisiforms represents a derived acceleration, suggesting that lineages in this group

305 evolved traits that allowed them to shift between trophic states more easily than other primates in

306 response to ecological conditions. The evolutionary importance of insects as a primary or

307 secondary dietary resource among lorisiforms was emphasized by Rasmussen \& Nekaris (1998),

308 who argued that adaptive divergence between Lorisidae and Galagidae in aspects of locomotor

309 behavior, sensory systems, and life history was driven, in part, by specialization on insects with

310 different properties: cryptic or toxic prey in the case of lorisids versus active and elusive prey in

311 the case of galagids. Notably, the ability to exploit insects has not necessarily channeled

312 lorisiform lineages toward obligate insectivory, as in tarsiers. The present-day expression of this

313 evolutionary history is the gradient of trophic strategies exhibited by galagids and the presence of

314 herbivorous and insectivorous lorisid sister lineages found in both Africa and Asia (Nekaris and

315 Bearder, 2007).

316 The second scenario posits that the transition rate found in lorisiforms is plesiomorphic

317 and that other primate clades evolved slower rates in parallel as they became more committed to

318 a particular trophic strategy: herbivory in Anthropoidea and Lemuriformes, and insectivory in

319 tarsiers. This scenario is less parsimonious than the first, but there are two lines of evidence that 
suggest convergent, herbivory-driven rate slowdowns in anthropoids and lemurs. First, as noted above, studies of chitinase genes indicate pervasive homoplasy in loss of function in these genes

322 across primates (Emerling et al., 2018; Janiak et al., 2018). Emerling et al. (2018) inferred that

323 the plesiomorphic number of CHIAs for placental mammals is five functional genes, and that

324 tarsiers retain this condition, implying that the last common ancestors of Primates and Haplorhini

325 also had five. The anthropoids and lemurs that have been characterized so far, including small-

326 bodied species, have two or fewer functional CHIAs, and some large-bodied species in both

327 clades have lost function in all five genes, indicating separate histories of increasing commitment

328 to herbivory (Emerling et al., 2018; Janiak et al., 2018). This conclusion is further reinforced by

329 the observation that the lorisiform Otolemur garnettii has three functional CHIAs (Emerling et

330 al., 2018; Janiak et al., 2018).

The second line of evidence suggesting convergent rate slowdowns in Anthropoidea and

332 Lemuriformes is the history of body-size evolution in each clade's smallest-bodied lineages. The

333 smallest anthropoids are the Callitrichinae, which have long been regarded as phyletic dwarfs

334 (e.g., Ford, 1980; Leutenegger, 1980; Rosenberger, 1992), descended from a common ancestor

335 shared with other platyrrhines that weighed approximately 1-2 kg (Ford \& Davis, 1992;

336 Montgomery \& Mundy, 2013; Silvestro et al., 2019). The closely related and slightly larger

337 squirrel monkeys (genus Saimiri) may also be dwarfed (Ford \& Davis, 1992; Rosenberger, 1992;

338 Silvestro et al., 2019). Recent studies of size evolution in lemurs have concluded that the

339 smallest members of this clade — species of the family Cheirogaleidae — have experienced

340 episodes of size reduction similar to those reconstructed for callitrichines (Masters, Génin,

341 Silvestro, Lister, \& DelPero, 2014; Montgomery \& Mundy, 2013). If these inferences of phyletic

342 dwarfism are correct, then the evolutionary histories of small-bodied anthropoids and lemurs 
343 may include long periods of relaxed selection on traits involved in extracting nutrition from

344 insects (e.g., chitinase genes) owing to the lesser importance of insects as a dietary resource at

345 large body size.

That most small-bodied anthropoids and lemurs have apparently entered their current size

347 range via phyletic dwarfism contrasts with the pattern evident in lorisiforms and tarsiers, where

348 small size appears to have prevailed throughout their histories (Beard, 1998; Beard, Qi, Dawson,

349 Wang, \& Li, 1994; Jaeger et al., 2010; Rossie, Ni, \& Beard, 2006; Steiper \& Seiffert, 2012;

350 Seiffert, Simons, \& Attia, 2003; Seiffert, Simons, Ryan, \& Attia, 2005). The observation that

351 tarsiers and at least some lorisiforms retain more functional CHIAs than other primates also

352 suggests long histories of small body size with selection to maintain some of the primitive

353 digestive machinery assembled in early insectivorous mammals (Emerling et al., 2018; Janiak et

354 al., 2018). Otolemur garnettii is the only lorisiform in which CHIAs have been investigated so

355 far (Emerling et al., 2018; Janiak et al., 2018). It is unclear how typical this galagid is of other

356 lorisiforms, but the fact that the number of functional genes retained by $O$. garnettii (three) is

357 intermediate between tarsiers (five) and anthropoids and lemurs (two or fewer) is consistent with

358 the idea that lorisiforms have experienced episodes of adaptation to herbivory without becoming

359 too specialized, resulting in a clade that has been more flexible than crown anthropoids,

360 lemuriforms, and tarsiers with regard to shifting between trophic strategies.

Thus, whereas the first scenario outlined above views a slow rate of trophic evolution and

362 commitment to herbivory as evolutionarily ancient and tied to the origin of crown primates, the

363 second scenario raises the possibility that trophic evolution in early crown primates was more

364 labile - similar to lorisiforms - before herbivory came to predominate in the case of crown

365 anthropoids and lemurs, and insectivory in the case of tarsiers. Such trophic flexibility is 
compatible with a last common ancestor of crown primates that was either primarily herbivorous

367 (Rosenberger, 2013; Sussman et al., 2013) or primarily insectivorous (Cartmill, 1974, 1992,

368 2012), and it implies that the ancestor's feeding adaptations did not necessarily constrain or bias

369 trophic evolution as the crown clade began to diversify in the late Paleocene and early Eocene.

\subsection{Evidence for trophic lability in the primate fossil record}

The primate fossil record provides some evidence that early small-bodied primates had a

373 greater tendency to shift between trophic states than would be inferred from the distribution of

374 states among extant anthropoids, lemurs, and tarsiers of similar size. Most of the small-bodied

375 primates known from the early and middle Eocene are omomyiforms (e.g., Covert, 1986;

376 Fleagle, 1978, 2013; Gilbert, 2005; Gingerich, 1981). Studies that have examined functional

377 aspects of molar form in this group indicate that it was characterized by a level of trophic

378 diversity similar to that found in extant lorisiforms (Strait, 2001). The evolutionary history of this

379 diversity is difficult to reconstruct with confidence, given uncertainties in the relationships

380 among omomyiform lineages (e.g., Morse et al., 2019; Tornow, 2008; Williams, 1994). Mapping

381 inferred diets onto the phylogenetic tree generated by Seiffert et al. (2018) indicates a minimum

382 of 5-7 shifts between trophic states over the course of approximately 20 million years (Figure 6).

383 By comparison, the minimum number of shifts required to explain the distribution of states

384 among extant primates is 10 across 60 million years or more of evolution (Scott, 2019),

385 suggesting a relatively high rate of trophic evolution in omomyiforms. This conclusion is also

386 supported by evidence for trophic diversity within two of the earliest genera-Teilhardina and

387 Steinius (Figure 6; Ni et al., 2004; Strait, 2001; Williams \& Covert, 1994). 
The broader significance of trophic evolution in omomyiforms is unclear owing to a lack of consensus regarding their phylogenetic relationships to the crown clades. Omomyiforms have been interpreted as stem tarsiers, stem haplorhines, or stem primates (see reviews in Fleagle, 2013; Martin, 1993; Miller, Gunnell, \& Martin, 2005). Rosenberger (2013), adopting the first of these alternatives as a working hypothesis, argued that trophic diversity within omomyiforms

393 reflects different stages in a shift from frugivory to the highly specialized form of insectivory

394 found in extant tarsiers. According to this view, the implications of omomyiform trophic

395 diversity are limited to the tarsier lineage, and the pattern of diversity mostly indicates a

396 directional macroevolutionary trend of increasing insectivory and its attendant morphological

397 adaptations. However, if omomyiforms are stem haplorhines (e.g., Kay, Ross, \& Williams, 1997)

398 or representatives of an early radiation of primates not uniquely related to any of the crown

399 clades (e.g., Martin, 1993; Miller et al., 2005), then their pattern of trophic diversity can be

400 plausibly interpreted as consistent with the hypothesis that trophic evolution in early primates

401 was more labile in comparison to crown Anthropoidea, Tarsiidae, and Lemuriformes.

403 omomyiforms and more specialized for herbivory. Adapiformes - the other major radiation of

404 primates known from the early and middle Eocene - are mostly large-bodied and are thought to

405 have filled the ecological niches that are now dominated by extant large-bodied anthropoids and

406 lemurs (i.e., diurnal herbivores) (Covert, 1986; Fleagle, 1978, 2013; Gilbert, 2005).

407 Nevertheless, there is some evidence for trophic diversity among early small-bodied members of 408 this group (e.g., Donrussellia, Asiadapis, and Marcgodinotius; Bajpai et al., 2008; Gilbert, 409 2005). A similar pattern may hold in anthropoids, especially if Eosimiidae are stem anthropoids 410 (Beard, Qi, Dawson, Wang, \& Li, 1994; Kay et al., 1997; Williams, Kay, \& Kirk, 2010; but see 
411 Miller et al., 2005). Small-bodied anthropoids from the late Eocene and early Oligocene have

412 been reconstructed as primarily frugivorous (Kirk \& Simons, 2001). In contrast, the molars of

413 middle Eocene eosimiids exhibit morphologies suggesting that these species were more

414 insectivorous than later anthropoids (cf. Heesy \& Ross, 2004; Kirk \& Simons, 2001) and perhaps

415 comparable to Saimiri, the most insectivorous extant anthropoid (Zimbler-DeLorenzo \& Stone,

416 2011; Table 1). Thus, although adapiforms and early anthropoids appear to have been largely

417 herbivorous radiations, there are hints of greater trophic diversity in the earliest members of

418 these clades, suggesting that trophic evolution may have been more labile before herbivory

419 became the dominant trophic strategy.

\section{$421 \quad 5 \mid$ CONCLUSIONS}

The results of this study indicate that the rate of trophic evolution in small-bodied

423 primates varies among clades. Contrary to expectations, small-bodied anthropoids do not have an

424 unusually low rate in comparison to other lineages. This finding challenges the hypothesis that

425 there is a direct connection between diurnality and the low frequency of insectivorous

426 anthropoids. The main contrast detected here involves lorisiforms, which have a much greater

427 tendency to shift between insectivory and herbivory than other primates. The implications of this

428 pattern of rate heterogeneity are unclear. The most parsimonious interpretation is that the

429 lorisiform rate is apomorphic, implying that primate trophic evolution has been conservative

430 throughout much of the clade's history. However, various lines of evidence suggest the

431 possibility of convergent rate slowdowns in anthropoids, lemuriforms, and tarsiers owing to

432 greater specialization for herbivory in the case of anthropoids and lemurs, and insectivory in the

433 case of tarsiers. These two scenarios can be tested as sampling of the earliest part of the primate 
434 fossil record increases, and as our understanding of the Eocene primate phylogeny and trophic

435 adaptations improves.

436

437 ACKNOWLEDGMENTS

438 I thank Thierra Nalley and Kristi Lewton for helpful comments on an earlier version of this

439 manuscript.

440

441 DATA AVAILABILITY STATEMENT

442 The data used for this study are available in Table S1 in the Supporting Information.

443

444 
445

446

447

448

449

450

451

452

453

454

455

\section{REFERENCES}

Bajpai, S., Kay, R. F., Williams, B. A., Das, D. P., Kapur, V. V., \& Tiwari, B. N. (2008). The oldest Asian record of Anthropoidea. Proceedings of the National Academy of Sciences of the United States of America, 105, 11093-11098.

Beard, K. C., Qi, T., Dawson, M. R., Wang, B., \& Li, C. (1994). A diverse new primate fauna from middle Eocene fissure-fillings in southeastern China. Nature, 368, 604-609

Barkman, T. J., Bendiksby, M., Lim, S.-H., Salleh, K. M., Nais, J., Madulid, D., \& Schumacher, T. (2008). Accelerated rates of floral evolution at the upper size limit for flowers. Current Biology, 18, 1508-1513.

Beard, K. C. (1998). A new genus of Tarsiidae (Mammalia: Primates) from the middle Eocene of Shanxi Province, China, with notes on the historical biogeography of tarsiers. Bulletin of Carnegie Museum of Natural History, 34, 260-277.

Beard, K. C., Qi, T., Dawson, M. R., Wang, B., \& Li, C. (1994). A diverse new primate fauna from middle Eocene fissure-fillings in southeastern China. Nature, 368, 604-609.

Beaudrot, L., Struebig, M. J., Meijaard, E., van Balen, S., Husson, S., \& Marshall, A. J. (2013a). Co-occurrence patterns of Bornean vertebrates suggest competitive exclusion is strongest among distantly related species. Oecologia, 173, 1053-1062.

Beaudrot, L., Struebig, M. J., Meijaard, E., van Balen, S., Husson, S., Young, C. F., \& Marshall, A. J. (2013b). Interspecific interactions between primates, birds, bats, and squirrels may affect community composition on Borneo. American Journal of Primatology, 75, 170185. 
Beaulieu, J. M., O’Meara, B. C., \& Donoghue, M. J. (2013). Identifying hidden rate changes in the evolution of a binary morphological character: the evolution of plant habit in campanulid angiosperms. Systematic Biology, 62, 725-737.

Biebouw, K. (2013). Preliminary results on the behavioral ecology of the hairy-eared dwarf lemur (Allocebus trochotis) in Andasibe, eastern Madagascar. In J. Masters, M. Gamba, \& F. Génin (Eds.), Leaping ahead: advances in prosimian biology (pp. 113-120). New York, NY: Springer.

Burrows, A. M., \& Nash, L. T. (2010). Searching for dental signals of exudativory in galagos. In A. M. Burrows \& L. T. Nash (Eds.), The evolution of exudativory in primates (pp. 211233). New York, NY: Springer.

Butynski, T. M., \& de Jong, Y. A. (2004). Natural history of the Somali lesser galago (Galago gallarum). Journal of East African Natural History, 93, 23-38.

Cartmill, M. (1974). Rethinking primate origins. Science, 184, 436-443.

Cartmill, M. (1980). Morphology, function, and evolution of the anthropoid postorbital septum. In R. L. Chiochon \& A. B. Chiarelli (Eds.), Evolution biology of the New World monkeys and continental drift (pp. 243-274). New York, NY: Plenum Press.

Cartmill, M. (1992). New views on primate origins. Evolutionary Anthropology, 1, 105-111.

Cartmill, M. (2012). Primate origins, human origins, and the end of higher taxa. Evolutionary Anthropology, 21, 208-220.

Charles-Dominique, P. (1975). Nocturnality and diurnality: an ecological interpretation of these two modes of life by an analysis of the higher vertebrate fauna in tropic forest ecosystems. In W. P. Luckett \& F. S. Szalay (Eds.), Phylogeny of the primates: a multidisciplinary approach (pp. 69-88). New York, NY: Plenum Press. 
Cooper, W. J, \& Steppan, S. J. (2010). Developmental constraint on the evolution of marsupial forelimb morphology. Australian Journal of Zoology, 58, 1-15.

Covert, H. H. (1986). Biology of early Cenozoic primates. In D. R. Swindler \& J. Erwin (Eds.), Comparative primate biology: Vol. 1. Systematics, evolution, and anatomy (pp. 335359). New York: Alan R. Liss.

Digby, L. J., Ferrari, S. F., \& Saltzman, W. (2007). Callitrichines: the role of competition in cooperatively breeding species. In C. J. Campbell, A. Fuentes, K. C. MacKinnon, M. Panger, \& S. K. Bearder (Eds.), Primates in perspective (pp. 85-105). Oxford: Oxford University Press.

dos Reis, M., Gunnell, G. F., Barba-Montoya, J., Wilkins, A., Yang, Z., \& Yoder, A.D. (2018). Using phylogenomic data to explore the effects of relaxed clocks and calibration strategies on divergence time estimation: primates as a test case. Systematic Biology, 67, 594-615.

Emerling, C. A., Delsuc, F., \& Nachman, M. W. (2018). Chitinase genes (CHIAs) provide genomic footprints of a post-Cretaceous dietary radiation in placental mammals. Science Advances, 4: eaar6478. DOI: 10.1126/sciadv.aar6478.

FitzJohn, R. G. (2012). Diversitree: comparative phylogenetic analyses of diversification in R. Methods in Ecology and Evolution, 3, 1084-1092.

Fleagle, J. G., (1978). Size distributions of living and fossil primate faunas. Paleobiology, 4, 6776.

Fleagle, J. G. (2013). Primate adaptation \& evolution (3rd ed.). San Diego, CA: Academic Press. Ford, S. M. (1980). Callitrichids as phyletic dwarfs, and the place of the Callitrichidae in Platyrrhini. Primates, 21, 31-43. 
512 Ford, S. M., \& Davis, L. C. (1992). Systematics and body size: implications for feeding

513

514

515 adaptations in New World monkeys. American Journal of Physical Anthropology, 88, $415-468$.

Génin, F., Yokwana, A., Kom, N., Couette, S., Dieuleveut, T., Nash, S. D., \& Masters, J. C. (2016). A new galago species for South Africa (Primates: Strepsirhini: Galagidae). African Zoology, 51, 135-143.

Gilbert, C. C. (2005). Dietary ecospace and the diversity of euprimates during the early and middle Eocene. American Journal of Physical Anthropology, 126, 237-249.

Gingerich, P. D. (1981). Early Cenozoic Omomyidae and the evolutionary history of tarsiiform primates. Journal of Human Evolution, 10, 345-374.

Goldberg, E. E., Kohn, J. R., Lande, R., Robertson, K. A., Smith, S. A., Igić, B. (2010). Species selection maintains self-incompatibility. Science, 330, 493-495.

Gómez, J. M., \& Verdú, M. (2012). Mutualism with plants drives primate diversification. Systematic Biology, 61, 567-577.

Gordon, A. D., Johnson, S. E., \& Louis, E. E., Jr. (2013). Females are the ecological sex: sexspecific body mass ecogeography in wild sifaka populations (Propithecus spp.). American Journal of Physical Anthropology, 151, 77-87.

Grossnickle, D. M. (2020). Feeding ecology has a stronger evolutionary influence on functional morphology than on body mass in mammals. Evolution, 74, 610-628.

Groves, C. P. (2005). Order Primates. In D. E. Wilson \& D. M. Reeder (Eds.), Mammal species of the world: a taxonomic and geographic reference (3rd ed., pp. 111-184). Baltimore, MD: Johns Hopkins University Press. 
534 Harcourt, C. S., \& Nash, L. T. (1986). Species differences in substrate use and diet between

535

536

537

538

539

540

541

542

543

544

545

546

547 sympatric galagos in two Kenyan coastal forests. Primates, 27, 41-52.

Heesy, C. P., \& Ross, C. F. (2004). Mosaic evolution of activity pattern, diet, and color vision in haplorhine primates. In C. F. Ross \& R. F. Kay (Eds.), Anthropoid origins: new visions (pp. 665-698). New York, NY: Kluwer Academic/Plenum Press.

Heymann, E. W., \& Hsia, S. S. (2015). Unlike fellows—a review of primate-non-primate associations. Biological Reviews, 90, 142-156.

Hladik, C. M., Charles-Dominique, P., \& Petter, J. J. (1980). Feeding strategies of five nocturnal prosimians in the dry forest of the west coast of Madagascar. In P. Charles-Dominique, H. M. Cooper, A. Hladik, C. M. Hladik, E. Pages, G. F. Pariente, A. Petter-Rousseaux, J. J. Petter, \& A. Schilling (Eds.), Nocturnal Malagasy primates: ecology, physiology, and behavior (pp. 41-73). New York, NY: Academic Press.

Jaeger, J.-J., Beard, K. C., Chaimanee, Y., Salem, M., Benammi, M., Hlal, O., ... Brunet, M. (2010). Late middle Eocene epoch of Libya yields earliest known radiation of African anthropoids. Nature, 467, 1095-1098).

Janiak, M. C., Chaney, M. E., \& Tosi, A. J. (2018). Evolution of acidic mammalian chitinase genes $(C H I A)$ is related to body mass and insectivory in primates. Molecular Biology \& Evolution, 35, 607-622.

Johnson, M. T. J., FitzJohn, R. G., Smith, S. D., Rausher, M. D., \& Otto, S. P. (2011). Loss of sexual recombination and segregation is associated with increased diversification in evening primroses. Evolution, 65, 3230-3240. 
Jones, K. E., Bielby, J., Cadillo, M., Fritz, S. A., O’Dell, J., Orme, C. D. L., ... Purvis, A. (2009). PanTHERIA: a species-level database of life history, ecology, and geography of extant and recently extinct mammals. Ecology, 90, 2648.

Jungers, W. L. (1984). Aspects of size and scaling in primate biology with special reference to the locomotor skeleton. Yearbook of Physical Anthropology, 27, 73-97.

Kay, R. F. (1975). The functional adaptations of primate molar teeth. American Journal of Physical Anthropology, 43, 195-216.

Kay, R. F., \& Covert, H. H. (1984). Anatomy and behavior of extinct primates. In D. J. Chivers, B. A. Wood, \& A. Bilsborough (Eds.), Food acquisition and processing in primates (pp. 467-508. New York, NY: Plenum Press.

Kay, R. F., \& Hylander, W. L. (1978). The dental structure of mammalian folivores with special reference to Primates and Phalangeroidea. In G. G. Montgomery (Ed.), The ecology of arboreal folivores (pp. 173-191). Washington, DC: Smithsonian Institution Press.

Kay, R. F., Ross, C., \& Williams, B. A. (1997). Anthropoid origins. Science, 275, 797-804.

Kay, R. F., \& Simons, E. L. (1980). The ecology of Oligocene African Anthropoidea. International Journal of Primatology, 1, 21-37.

Kinzey, W. G. (1992). Dietary and dental adaptations in the Pitheciinae. American Journal of Physical Anthropology, 88, 499-514.

Kirk, E. C., \& Simons, E. L. (2001). Diets of fossil primates from the Fayum Depression of Egypt: a quantitative analysis of molar shearing. Journal of Human Evolution, 40, 203229.

Lambert, J. E. (1998). Primate digestion: interactions among anatomy, physiology, and feeding ecology. Evolutionary Anthropology, 7, 8-20. 
578 Leutenegger, W. (1980). Monogamy in callitrichids: a consequence of phyletic dwarfism? International Journal of Primatology, 1, 95-98.

Litsios, G., Pellissier, L., Forest, F., Lexer, C., Pearman, P. B., Zimmerman, N. E., \& Salamin, N. (2012). Trophic specialization influences the rate of environmental niche evolution in

Maddison, W. P., \& Maddison, D. R. (2019). Mesquite: a modular system for evolutionary analysis (version 3.61). Available from http://www.mesquiteproject.org.

Magnuson-Ford, K., \& Otto, S. P. (2012). Linking the investigations of character evolution and species diversification. American Naturalist, 180, 225-245.

Martin, R. D. (1993). Primate origins: plugging the gaps. Nature, 363, 223-234.

Masters, J. C., Génin, F., Silvestro, D., Lister, A. M., \& DelPero, M. (2014). The red island and the seven dwarfs: body size reduction in Cheirogaleidae. Journal of Biogeography, 41, $1833-1847$.

McNab, B. K. (1984). Physiological convergence amongst ant-eating and termite-eating

Miller, E. R., Gunnell, G. F., \& Martin, R. D. (2005). Deep time and the search for anthropoid origins. Yearbook of Physical Anthropology, 48, 60-95.

Montgomery, S. H., \& Mundy, N. I. (2013). Parallel episodes of phyletic dwarfism in callitrichid and cheirogaleid primates. Journal of Evolutionary Biology, 26, 810-819. (2019). New fossils, systematics, and biogeography of the oldest known crown primate Teilhardina from the earliest Eocene of Asia, Europe, and North America. Journal of Human Evolution, 128, 103-131. 
601 Nakov, T., Beaulieu, J. M., \& Alverson, A. J. (2019). Diatoms diversify and turn over faster in freshwater than marine environments. Evolution, 73, 2497-2511.

Nash, L. T., Bearder, S. K., \& Olson, T.R. (1989). Synopsis of Galago species characteristics. International Journal of Primatology, 10, 57-80.

Nekaris, K. A. I., \& Bearder, S. K. (2007). The lorisiform primates of Asia and mainland Africa. Primates in perspective (pp. 24-45). Oxford: Oxford University Press.

Niemitz, C. (1984). Synecological relationships and feeding behaviour of the genus Tarsius. In C. Niemitz (Ed.), Biology of tarsiers (pp. 59-75). Stuttgart: Gustav Fischer Verlag.

612 Plummer, M., Best, N., Cowles, K., \& Vines, K. (2006). CODA: convergence diagnosis and output analysis for MCMC. R News, 6, 7-11.

614 Price, S. A., \& Hopkins, S. S. B. (2015). The macroevolutionary relationship between diet and body mass across mammals. Biological Journal of the Linnean Society, 115, 173-184.

616 Rasmussen, D. T., \& Nekaris, K. A. (1998). Evolutionary history of lorisiform primates. Folia Primatologica, 69(Suppl. 1), 250-285.

618 R Core Team (2019). R: a language and environment for statistical computing. Vienna, Austria: R Foundation for Statistical Computing. https://www.R-project.org/.

620 Rosenberger, A. L. (1992). Evolution of feeding niches in New World monkeys. American Journal of Physical Anthropology, 88, 525-562.

622 Rosenberger, A. L. (2013). Fallback foods, preferred foods, adaptive zones, and primate origins. 
624 Ross, C. (1996). Adaptive explanation for the origins of the Anthropoidea (Primates). American Journal of Primatology, 40, 205-230.

626 Rossie, J. B., Ni, X., Beard, K. C. (2006). Cranial remains of an Eocene tarsier. Proceedings of the National Academy of Sciences of the United States of America, 103, 4381-4385.

Rovero, F., Marshall, A. R., Jones, T., \& Perkin, A. (2009). The primates of Udzungwa Mountains: diversity, ecology and conservation. Journal of Anthropological Sciences, 87,

631 Santini, L., Rojas, D., \& Donati, G. (2015). Evolving through day and night: origin and diversification of activity pattern in modern primates. Behavioral Ecology, 26, 789-796.

Scott, J. E. (2018). Reevaluating cases of trait-dependent diversification in primates. American Journal of Physical Anthropology, 167, 244-256.

Scott, J. E. (2019). Macroevolutionary effects on primate trophic evolution and their implications for reconstructing primate origins. Journal of Human Evolution, 133, 1-12.

637 Seiffert, E. R., Simons, E. L., \& Attia, Y. (2003). Fossil evidence for ancient divergence of lorises and galagos. Nature, 422, 421-424.

639 Seiffert, E. R., Boyer, D. M., Fleagle, J. G., Gunnell, G. F., Heesy, C. P., Perry, J. M. G., \& Sallam, H. M. (2018). New adapiform primate fossil from the late Eocene of Egypt.

642 Seiffert, E. R., Simons, E. L., Ryan, T. M., \& Attia, Y. (2005). Additional remains of Wadilemur elegans, a primitive stem galagid from the late Eocene of Egypt. Proceedings of the 
Silvestro, D., Tejedor, M. F., Serrano-Serrano, M. L., Loiseau, O., Rossier, V., Rolland, J., ... Salamin, N. (2019). Early arrival and climatically-linked geographic expansion of New World monkeys from tiny African ancestors. Systematic Biology, 68, 78-92.

Smith, R. J., \& Jungers, W. L. (1997). Body mass in comparative primatology. Journal of Human Evolution, 32, 523-559.

Souza-Alves, J. P., Fontes, I. P., Chagas, R. R. D., \& Ferrari, S. F. (2011). Seasonal versatility in the feeding ecology of a group of titis (Callicebus coimbrai) in the northern Brazilian Atlantic Forest. American Journal of Primatology, 73, 1199-1209.

Springer, M. S., Meredith, R. W., Gatesy, J., Emerling, C. A., Park, J., Rabosky, D. L., ... Murphy, W. J. (2012). Macroevolutionary dynamics and historical biogeography of primate diversification inferred from a species supermatrix. PLOS ONE, 7, e49521. DOI: 10.1371/journal.pone.0049521.

Steiper, M. E., \& Seiffert, E. R. (2012). Evidence for a convergent slowdown in primate molecular rates and its implications for the timing of early primate evolution. Proceedings of the National Academy of Sciences of the United States of America, 109, 6006-6011.

Strait, S. G. (2001). Dietary reconstruction of small-bodied omomyoid primates. Journal of Vertebrate Paleontology, 21, 322-334.

Sussman, R. W. (1991). Primate origins and the evolution of angiosperms. American Journal of Primatology, 23, 209-223.

Sussman, R. W., Rasmussen, D. T., \& Raven, P. H. (2013). Rethinking primate origins again. American Journal of Primatology, 75, 95-106.

Szalay, F. S. (1968). The beginnings of primates. Evolution, 22, 19-36. 
668 Tornow, M. A. (2008). Systematic analysis of the Eocene primate Omomyidae using gnathic and postcranial data. Bulletin of the Peabody Museum of Natural History, 49, 43-129.

670 Williams, B. A. (1994). Phylogeny of the Omomyidae and implications for anthropoid origins

671 (Unpublished doctoral dissertation). University of Colorado, Boulder.

672 Williams, B. A., \& Covert, H. H. (1994). New early Eocene anaptomorphine primate

673 (Omomyidae) from the Washakie Basin, Wyoming, with comments on the phylogeny and paleobiology of anaptomorphines. American Journal of Physical Anthropology, 93, $323-340$.

676 Williams, B. A., Kay, R. F., \& Kirk, E. C. (2010). New perspectives on anthropoid origins. Proceedings of the National Academy of Sciences of the United States of America, 107, 4797-4804.

679 Zimbler-DeLorenzo, H. S., \& Stone, A. I. (2011). Integration of field and captive studies for 680 understanding the behavioral ecology of the squirrel monkey (Saimiri sp.). American Journal of Primatology, 73, 607-622. 


\section{FIGURE CAPTIONS}

685 FIGURE 1. Primate phylogenetic tree from Springer et al. (2012) showing the distribution of

686 trophic states by activity pattern among small-bodied species $(<1 \mathrm{~kg})$ at the tips (Scott, 2019).

687 Cathemeral species are grouped with diurnal species. Large-bodied species, which are uniformly

688 herbivorous and mostly diurnal, are not labeled. The relative frequency of insectivorous species

689 is much greater among nocturnal lineages (41.5\%) than among diurnal lineages (9.5\%).

691 FIGURE 2. Posterior distributions of trophic transition rates (A) and size transition rates (B, C)

692 for the model with Anthropoidea split from the rest of the tree and a size threshold of $800 \mathrm{~g}$. The

693 results shown here were generated using the timetree that assumed autocorrelated rates and soft-

694 bounded constraints. Anth $=$ Anthropoidea, Tars $=$ Tarsiiformes, Lem $=$ Lemuriformes, Lor $=$

695 Lorisiformes, $q=$ transition rate, $\mathrm{SL}=$ small to large, $\mathrm{LS}=$ large to small.

697 FIGURE 3. Posterior distributions of trophic transition rates for the model with Lorisiformes

698 split from the rest of the tree and a size threshold of $800 \mathrm{~g}$. The results shown here were

699 generated using the timetree that assumed autocorrelated rates and soft-bounded constraints.

700 Anth $=$ Anthropoidea, Tars $=$ Tarsiiformes, Lem $=$ Lemuriformes, Lor $=$ Lorisiformes,$q=$

701 transition rate.

702

703 FIGURE 4. Posterior distributions of trophic transition rates for the model with Lemuriformes

704 split from the rest of the tree and a size threshold of $800 \mathrm{~g}$. The results shown here were

705 generated using the timetree that assumed autocorrelated rates and soft-bounded constraints. 
Anth $=$ Anthropoidea, Tars $=$ Tarsiiformes, Lem $=$ Lemuriformes, Lor $=$ Lorisiformes,$q=$

707 transition rate.

708

FIGURE 5. Posterior distributions of trophic transition rates for the model with Anthropoidea and Lorisiformes each split from the rest of the tree and a size threshold of $800 \mathrm{~g}$. The results

711 shown here were generated using the timetree that assumed autocorrelated rates and soft-

712 bounded constraints. Anth $=$ Anthropoidea, Tars $=$ Tarsiiformes, Lem $=$ Lemuriformes, Lor $=$ 713 Lorisiformes, $q=$ transition rate.

FIGURE 6. Phylogenetic distribution of trophic strategies among early and middle Eocene

716 omomyiform genera. Dietary reconstructions for each genus are based mainly on the work of

717 Strait (2001), with additional information from Ni, Wang, Hu, \& Li (2004) and Williams \&

718 Covert (1994). Parsimony reconstructions of diet, obtained using Mesquite (v. 3.61; Maddison \&

719 Maddison, 2019), indicate a minimum of 5-7 shifts between trophic states, depending on how

720 ambiguous taxa are coded. The reconstructions shown here are based on the data set where

721 Bownomomys and Dyseolemur were coded as ambiguous (see Strait, 2001). The tree was taken

722 from the Bayesian tip-dating phylogenetic analysis conducted by Seiffert et al. (2018; see their

723 figure 17). Branch lengths are proportional to time; the tree spans approximately 20 million years

724 from root to most recent tip (Necrolemur). Teilhardina includes T. asiatica and T. belgica;

725 Steinius includes S. vespertinus and S. annectens; the use of Bownomomys here follows Morse et

726 al. (2019) and is equivalent to Teilhardina americana in previous studies. See Strait (2001) and

727 Seiffert et al. (2018) for the complete lists of species-level taxa. 
TABLE 1 Primates classified as insectivorous for this study

\begin{tabular}{|c|c|c|}
\hline Species & $\%$ Faunivory & Source \\
\hline Galagoides thomasi & 70 & Nekaris \& Bearder, 2007 \\
\hline Galagoides demidoff & 70 & Nekaris \& Bearder, 2007 \\
\hline Galago matschiei & qualitative $^{\dagger}$ & Nash, Bearder, \& Olson, 1989 \\
\hline Galago moholi & 52 & Nekaris \& Bearder, 2007 \\
\hline Galago gallarum & qualitative $^{\dagger}$ & Butynski \& de Jong, 2004 \\
\hline Galago senegalensis & 50 & Burrows \& Nash, 2010 \\
\hline Paragalago orinus & qualitative $^{\dagger}$ & Rovero, Marshall, Jones, \& Perkin, 2009 \\
\hline Paragalago granti & qualitative $^{\dagger}$ & Génin et al., 2016 \\
\hline Paragalago zanzibaricus & 70 & Harcourt \& Nash, 1986 \\
\hline Otolemur garnettii & 50 & Harcourt \& Nash, 1986 \\
\hline Loris lydekkerianus & 96 & Nekaris \& Bearder, 2007 \\
\hline Loris tardigradus & 100 & Nekaris \& Bearder, 2007 \\
\hline Arctocebus calabarensis & 85 & Rothman et al., 2014 \\
\hline Arctocebus aureus & 85 & Rothman et al., 2014 \\
\hline Allocebus trichotis & 70 & Biebouw, 2013 \\
\hline Mirza coquereli & $>50$ & Hladik, Charles-Dominique, \& Petter, 1980 \\
\hline Microcebus rufus & 54 & Rothman et al., 2014 \\
\hline Tarsius dentatus & 100 & Niemitz, 1984 \\
\hline Tarsius tarsier & 100 & Niemitz, 1984 \\
\hline Tarsius sangirensis & 100 & Niemitz, 1984 \\
\hline Cephalopachus bancanus & 100 & Niemitz, 1984 \\
\hline Carlito syrichta & 100 & Niemitz, 1984 \\
\hline Saimiri sciureus & 79-97 & Zimbler-DeLorenzo \& Stone, 2011 \\
\hline Saimiri oerstedii & 90 & Zimbler-DeLorenzo \& Stone, 2011 \\
\hline Saimiri boliviensis & 75 & Zimbler-DeLorenzo \& Stone, 2011 \\
\hline Saimiri ustus & as for other Saimiri & Zimbler-DeLorenzo \& Stone, 2011 \\
\hline
\end{tabular}

$\dagger$ For some species, dietary percentages were not available. In such cases, I used qualitative accounts from experts as long as the description was consistent with quantitative data for the species' closest living relatives. See Table S1 in the Supporting Information for the full sample. 
TABLE 2 Support for trophic-rate differences in two-partition models

\begin{tabular}{|c|c|c|c|c|}
\hline \multirow[b]{3}{*}{ Model comparison } & \multicolumn{4}{|c|}{ Posterior probability } \\
\hline & \multicolumn{2}{|c|}{ AUTOsoft tree } & \multicolumn{2}{|c|}{ AUTOhard tree } \\
\hline & t. 800 & t. 1000 & t. 800 & t. 1000 \\
\hline Anthropoidea < background & 0.917 & 0.959 & 0.906 & 0.946 \\
\hline Lorisiformes $>$ background & 0.985 & 0.992 & 0.983 & 0.989 \\
\hline Lemuriformes $>$ background & 0.622 & 0.676 & 0.614 & 0.647 \\
\hline
\end{tabular}

Notation: AUTOsoft $=$ autocorrelated rates of molecular evolution and soft-bounded constraints; AUTOhard $=$ autocorrelated rates of molecular evolution and hard-bounded constraints; t. $800=$ size threshold of $800 \mathrm{~g} ; \mathrm{t} .1000=$ size threshold of $1 \mathrm{~kg}$.

TABLE 3 Support for trophic-rate differences in the three-partition model

\begin{tabular}{lccccc} 
& \multicolumn{4}{c}{ Posterior probability } \\
\cline { 2 - 3 } \cline { 5 - 6 } Model comparison & \multicolumn{2}{c}{ AUTOsoft tree } & & \multicolumn{2}{c}{ AUTOhard tree } \\
\cline { 2 - 3 } Anthropoidea < background & 0.700 & t.1000 & & t.800 & t.1000 \\
Loriformes > background & 0.939 & 0.861 & & 0.787 & 0.838 \\
Lorisformes > Anthropoidea & 0.986 & 0.995 & & 0.933 & 0.950 \\
\hline
\end{tabular}

Notation: AUTOsoft $=$ autocorrelated rates of molecular evolution and soft-bounded constraints; AUTOhard $=$ autocorrelated rates of molecular evolution and hard-bounded constraints; t. $800=$ size threshold of $800 \mathrm{~g}$; t.1000 = size threshold of $1 \mathrm{~kg}$. 


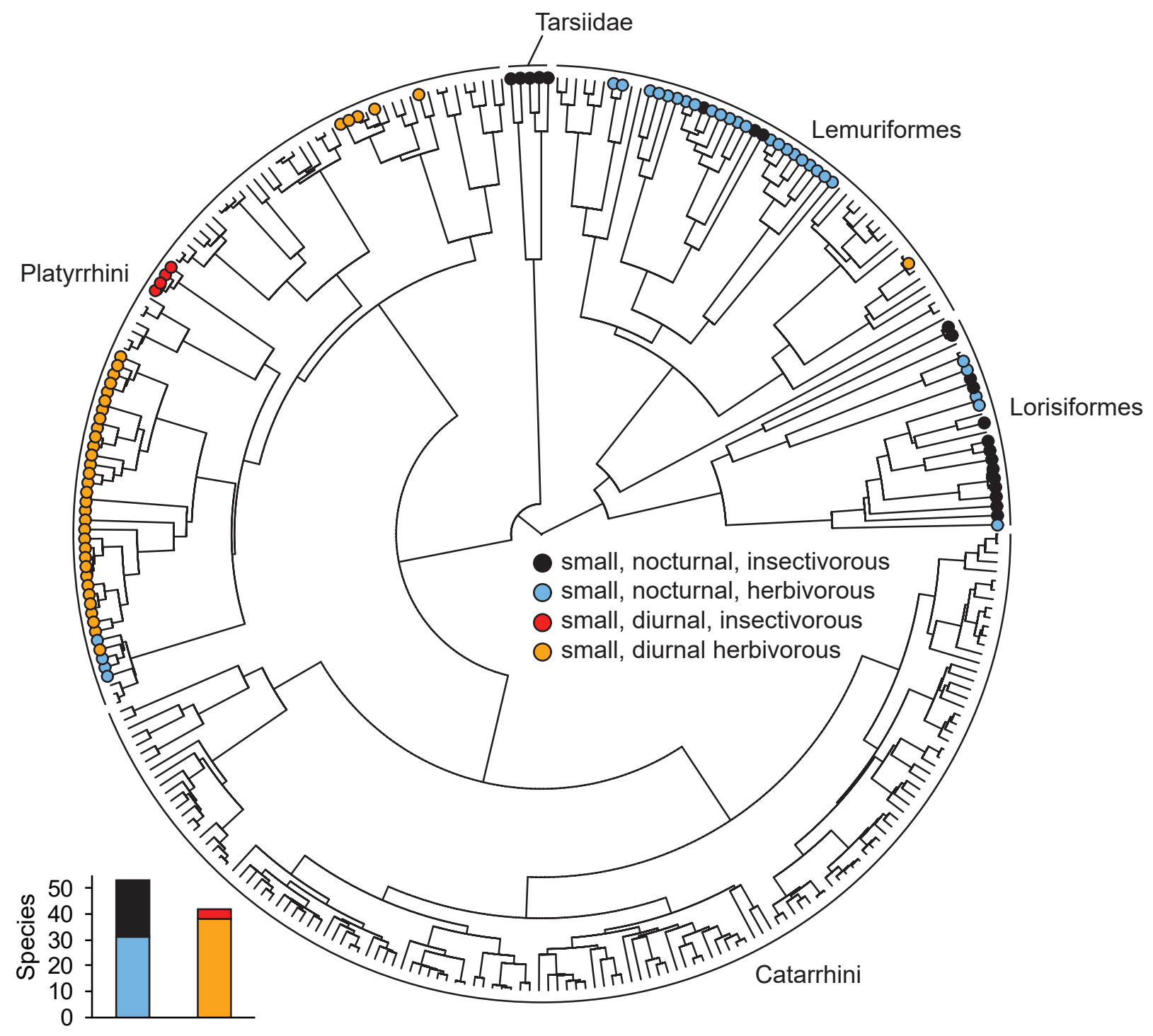

FIGURE 1. Primate phylogenetic tree from Springer et al. (2012) showing the distribution of trophic states by activity pattern among small-bodied species ( $<1 \mathrm{~kg})$ at the tips (Scott, 2019). Cathemeral species are grouped with diurnal species. Large-bodied species, which are uniformly herbivorous and mostly diurnal, are not labeled. The relative frequency of insectivorous species is much greater among nocturnal lineages (41.5\%) than among diurnal lineages (9.5\%). 

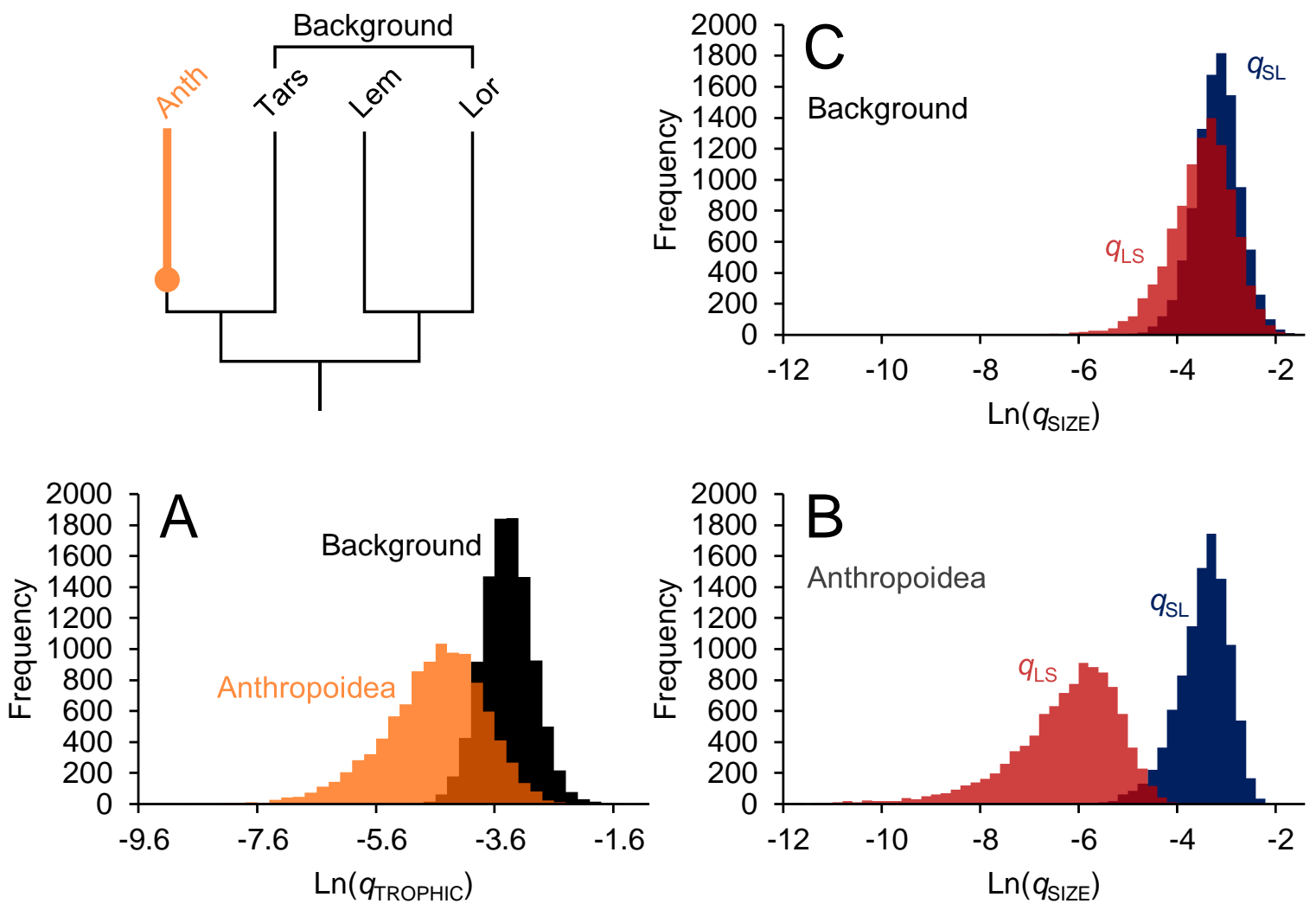

FIGURE 2. Posterior distributions of trophic transition rates $(A)$ and size transition rates $(B, C)$ for the model with Anthropoidea split from the rest of the tree and a size threshold of $800 \mathrm{~g}$. The results shown here were generated using the timetree that assumed autocorrelated rates and soft-bounded constraints. Anth = Anthropoidea, Tars $=$ Tarsiiformes, Lem $=$ Lemuriformes, Lor $=$ Lorisiformes, $q=$ transition rate, $\mathrm{SL}=$ small to large, $\mathrm{LS}=$ large to small. 

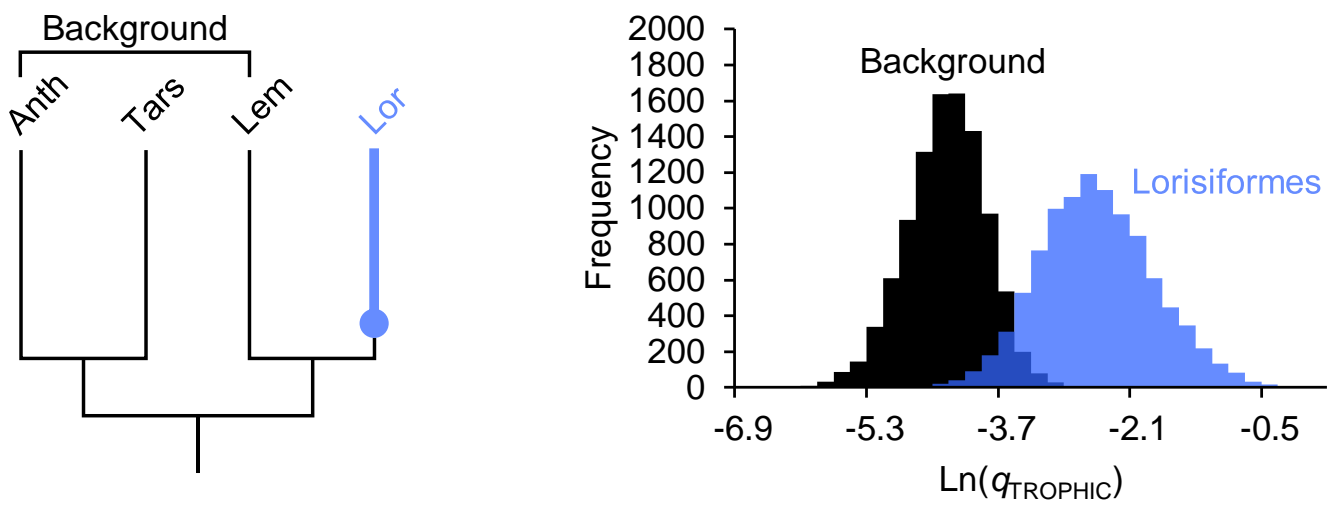

FIGURE 3. Posterior distributions of trophic transition rates for the model with Lorisiformes split from the rest of the tree and a size threshold of $800 \mathrm{~g}$. The results shown here were generated using the timetree that assumed autocorrelated rates and soft-bounded constraints. Anth $=$ Anthropoidea, Tars $=$ Tarsiiformes, Lem $=$ Lemuriformes, Lor $=$ Lorisiformes, $q=$ transition rate. 

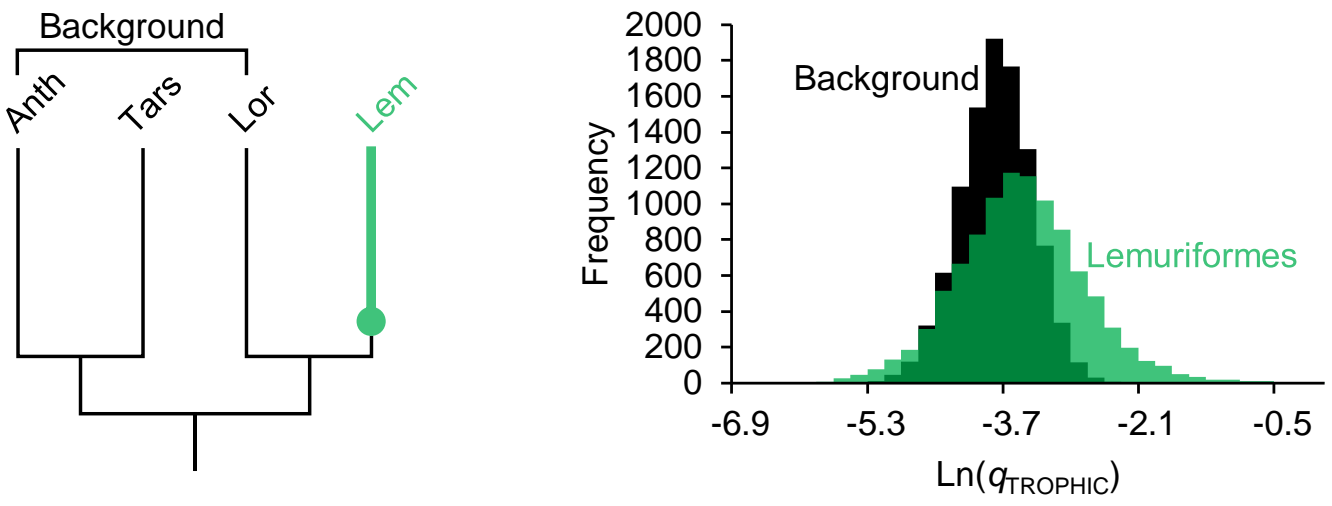

FIGURE 4. Posterior distributions of trophic transition rates for the model with Lemuriformes split from the rest of the tree and a size threshold of $800 \mathrm{~g}$. The results shown here were generated using the timetree that assumed autocorrelated rates and soft-bounded constraints. Anth $=$ Anthropoidea, Tars $=$ Tarsiiformes, Lem $=$ Lemuriformes, Lor $=$ Lorisiformes, $q=$ transition rate. 

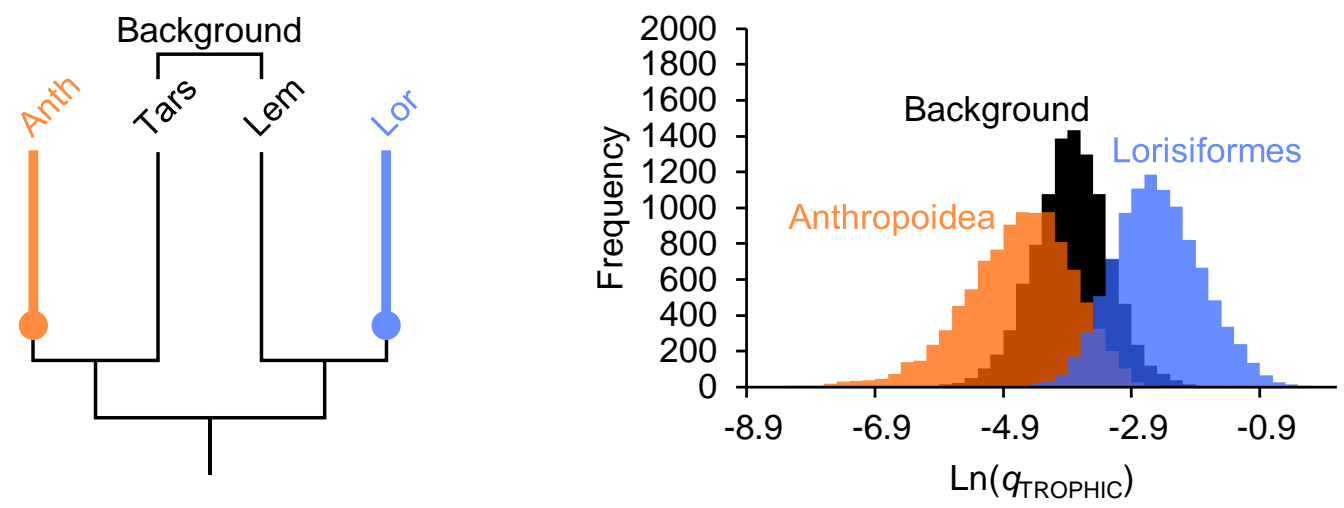

FIGURE 5. Posterior distributions of trophic transition rates for the model with Anthropoidea and Lorisiformes each split from the rest of the tree and a size threshold of $800 \mathrm{~g}$. The results shown here were generated using the timetree that assumed autocorrelated rates and softbounded constraints. Anth $=$ Anthropoidea, Tars $=$ Tarsiiformes, Lem $=$ Lemuriformes, Lor $=$ Lorisiformes, $q=$ transition rate. 


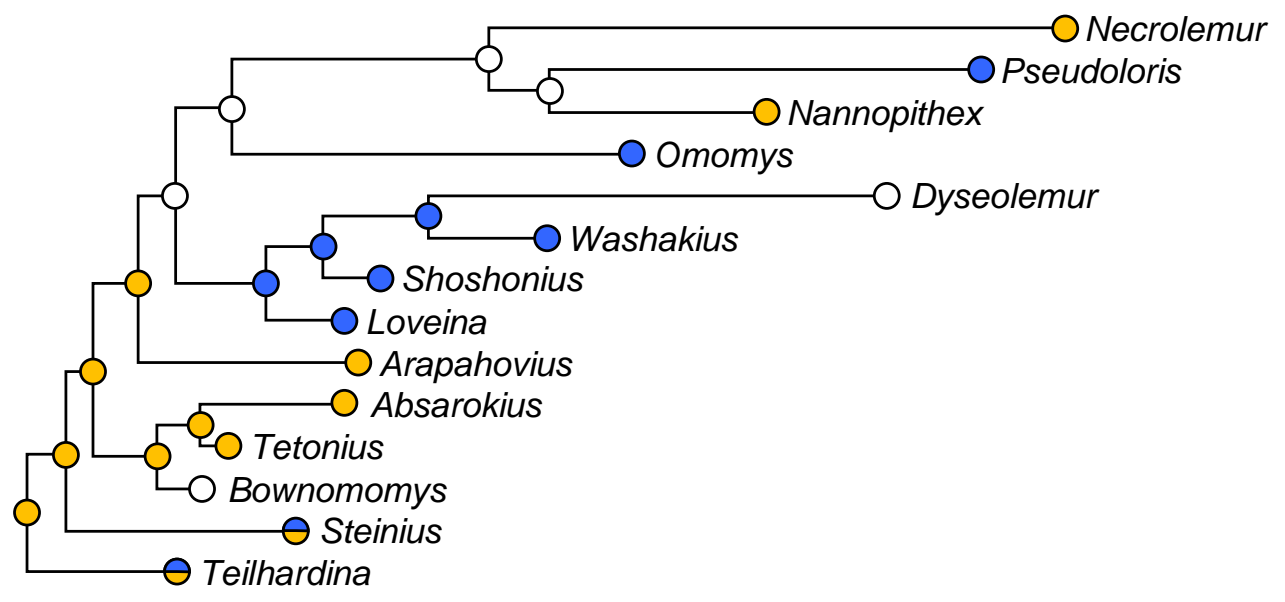

Primarily frugivorous

Primarily insectivorous

Genus contains both trophic strategies

Ambiguous

FIGURE 6. Phylogenetic distribution of trophic strategies among early and middle Eocene omomyiform genera. Dietary reconstructions for each genus are based mainly on the work of Strait (2001), with additional information from Ni, Wang, Hu, \& Li (2004) and Williams \& Covert (1994). Parsimony reconstructions of diet, obtained using Mesquite (v. 3.61; Maddison \& Maddison, 2019), indicate a minimum of 5-7 shifts between trophic states, depending on how ambiguous taxa are coded. The reconstructions shown here are based on the data set where Bownomomys and Dyseolemur were coded as ambiguous (see Strait, 2001). The tree was taken from the Bayesian tip-dating phylogenetic analysis conducted by Seiffert et al. (2018; see their figure 17). Branch lengths are proportional to time; the tree spans approximately 20 million years from root to most recent tip (Necrolemur). Teilhardina includes $T$. asiatica and $T$. belgica; Steinius includes S. vespertinus and S. annectens; the use of Bownomomys here follows Morse et al. (2019) and is equivalent to Teilhardina americana in previous studies. See Strait (2001) and Seiffert et al. (2018) for the complete lists of species-level taxa. 